\section{THU0301 SAFETY FOLLOWING INITIATION OF RITUXIMAB IN GRANULOMATOSIS WITH POLYANGIITIS (GPA) OR MICROSCOPIC POLYANGIITIS (MPA): INTERIM ANALYSIS OF THE RITUXIMAB IN ANCA-ASSOCIATED VASCULITIS REGISTRY (RAVER)}

J. Niles $^{1}$, N. Allen ${ }^{2}$, J.A. Block ${ }^{3}$, C.L. Koening ${ }^{4}$, C.A. Langford ${ }^{5}$, A. Abrill ${ }^{6}$, A.S. Lee ${ }^{6}$, P.A. Merkel ${ }^{7}$, L.E. Mertz ${ }^{8}$, P.A. Monach ${ }^{9}$, L.W. Moreland ${ }^{10}$, P.H. Nachman ${ }^{11}$, T. Peikert ${ }^{8}$, R.F. Spiera ${ }^{12}$, D. Wallace ${ }^{13}$, F. Erblang ${ }^{14}$ M.D. Cascino ${ }^{15}$, P. Duncombe ${ }^{16}$, V. Malik ${ }^{14}$, P. Brunetta ${ }^{15} .{ }^{1}$ Massachusetts General Hospital, Boston, MA; ${ }^{2}$ Duke University Medical Center, Durham, NC; ${ }^{3}$ Rush University Medical Center, Chicago, IL; ${ }^{4}$ University of Utah, Salt Lake City, UT; ${ }^{5}$ Cleveland Clinic Foundation, Cleveland, $\mathrm{OH} ;{ }^{6}$ Mayo Clinic, Jacksonville, FL; ${ }^{7}$ University of Pennsylvania, Philadelphia, PA; ${ }^{8}$ Mayo Clinic, Rochester, MN; ${ }^{9}$ Boston Medical Center, Boston, MA; ${ }^{10}$ University of Pittsburgh School of Medicine, Pittsburgh, PA; ${ }^{11}$ University of North Carolina, Chapel Hill, NC; ${ }^{12}$ Hospital for Special Surgery, New York, NY; ${ }^{13}$ Wallace Rheumatic Disease Research Center, Los Angeles, CA, United States; ${ }^{14} \mathrm{~F}$. Hoffmann La-Roche, Ltd., Basel, Switzerland; ${ }^{15}$ Genentech, Inc., South San Francisco, CA, United States; ${ }^{16}$ prn Statistical Consulting Services, Ltd., Ely, United Kingdom

Background: Therapy-related serious adverse events (SAEs) are important causes of morbidity in patients with GPA or MPA. Long-term safety data of rituximab in GPA/MPA are limited.

Objectives: To characterize safety events in an observational registry of patients with GPA/MPA initiating rituximab.

Methods: This interim analysis of RaVeR, an ongoing open-label real-world study of adult patients with GPA or MPA initiating rituximab (dose/frequency determined by investigator), was conducted when $50 \%$ of patient-years (PY) were collected (July 2015). Safety events included serious infections (SI), infusionrelated reactions (IRR), serious cardiac events, malignancies, and other serious events. Crude incidence rates (IR) and $95 \% \mathrm{Cl}$ were calculated. Trial registration number: NCT01613599

Results: 97 patients (291 PY) received rituximab, of whom $70 \%$ received rituximab retreatment. Median follow-up was 2.4 years. Overall, $91 \%$ of patients were ANCApositive and $78 \%$ had GPA. 17 patients $(17.5 \%)$ had a history of plasmapheresis or dialysis; $20(20.6 \%)$ were receiving rituximab plus cyclophosphamide at baseline. 33 patients had 71 SAEs (32.4/100 PYs [95\% Cl: 25.32-40.89]). 11 patients had 20 SIs (9.13/100 PYs [95\% Cl: 5.58-14.10]). 9 patients (9.3\%) experienced 13 serious cardiovascular (CV) events (5.93/100 PYs [95\% Cl: 3.16-10.15]), 12 of which were reported as unrelated to rituximab. Of the $13 \mathrm{CV}$ events, 9 were atrial arrhythmias and most patients had associated renal or CV disease history. There were no serious IRRs or SAEs within 24 hours of rituximab infusion. There were 6 deaths (2.74/100 PYs [95\% Cl: 1.01-5.96]); causes of death included septic shock, interstitial lung disease, congestive heart failure, cardio-respiratory arrest and 2 deaths of unknown etiology. The severe disease flare rate was 5.94/100 PYs (95\% Cl: 3.16-10.15). Among patients who received rituximab retreatment, the IRs of SAEs (26.1/100 PYs) and Sls (7.29/100 PYs) were not increased compared with the overall cohort.

\begin{tabular}{lcc}
\multicolumn{3}{l}{ Table. Observed safety events of interest } \\
\hline & Number of events & IR per $100 \mathrm{PY}(95 \% \mathrm{Cl})$ \\
All SAEs & 71 in $33 \mathrm{pts}(34 \%)$ & $32.42(25.3$ to 40.9$)$ \\
Serious infections & 20 in $11 \mathrm{pts}(11 \%)$ & $9.13(5.58$ to 14.1$)$ \\
Serious cardiac events & 13 in 9 pts $(9 \%)$ & $5.93(3.16$ to 10.15$)$ \\
Serious vascular events & 6 in 5 pts $(5 \%)$ & $2.74(1.01$ to 5.96$)$ \\
Malignancies & 2 in 2 pts $(2 \%)$ & $0.91(0.11$ to 3.30$)$ \\
\hline IR, incidence rate; PY, patient-year; SAE, serious adverse event.
\end{tabular}

Conclusions: In this interim analysis of patients with GPA/MPA treated with rituximab, SAEs were not increased compared with comparable cohorts of patients with renal involvement. Safety events did not increase with rituximab retreatment. These results are consistent with the known safety profile of rituximab and provide preliminary long-term, practice-level safety data for rituximab in GPA/MPA.

Acknowledgements: This study was funded by F. Hoffmann-La Roche, Ltd.

Disclosure of Interest: J. Niles: None declared, N. Allen Grant/research support from: Genentech, Inc., J. Block: None declared, C. Koening Grant/research support from: VA Merit, C. Langford: None declared, A. Abril: None declared, A. Lee: None declared, P. Merkel: None declared, L. Mertz: None declared, P. Monach Grant/research support from: Genentech, Inc.; Bristol-Meyers Squibb; GlaxoSmithCline, Speakers bureau: Medscape, L. Moreland Grant/research support from: Genentech, Inc.; Pfizer; Bristol-Meyers Squibb, Consultant for: Pfizer; Boehringer Ingeheim, P. Nachman: None declared, T. Peikert: None declared, R. Spiera: None declared, D. Wallace: None declared, F. Erblang Employee of: F. Hoffmann-La Roche, Ltd., M. Cascino Employee of: Genentech, Inc., P. Duncombe Shareholder of: prn Statistical Consulting Services, Ltd., V. Malik Employee of: F. Hoffmann-La Roche, Ltd., P. Brunetta Employee of: Genentech, Inc.

DOI: 10.1136/annrheumdis-2017-eular.1177

\section{THU0302 HISTOLOGY FINDINGS IN GIANT CELL ARTERITIS (GCA) AND THEIR RELATIONSHIP WITH THE ULTRASOUND RESULTS: ANALYSIS OF DATA FROM THE TABUL STUDY (TEMPORAL ARTERY BIOPSY VS ULTRASOUND IN DIAGNOSIS OF GIANT CELL ARTERITIS)}

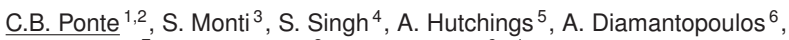
B. Dasgupta ${ }^{7}$, W.A. Schmidt ${ }^{8}$, R.A. Luqmani ${ }^{9} .{ }^{1}$ Department of Rheumatology, Hospital de Santa Maria; ${ }^{2}$ Rheumatology Research Unit, Instituto de Medicina Molecular, Faculdade de Medicina da Universidade de Lisboa, Lisbon, Portugal; ${ }^{3}$ Department of Rheumatology, IRCCS Policlinico S. Matteo Foundation, University of Pavia, Pavia, Italy; ${ }^{4}$ Nuffield Department of Surgical Sciences, University of Oxford, Oxford; ${ }^{5}$ Department of Health Services Research and Policy, London School of Hygiene and Tropical Medicine, London, United Kingdom; ${ }^{6}$ Department of Rheumatology, Hospital of Southern Norway Trust, Kristiansand, Norway; ${ }^{7}$ Department of Rheumatology, Southend University Hospital, NHS Foundation Trust, Southend-on-Sea, United Kingdom;

${ }^{8}$ Department of Rheumatology, Immanuel Krankenhaus Berlin, Medical Centre for Rheumatology Berlin-Buch, Berlin, Germany; ${ }^{9}$ Nuffield Department of Orthopaedics Rheumatology and Musculoskeletal Sciences, University of Oxford, Oxford, United Kingdom

Background: Although temporal artery biopsy (TAB) has been the gold standard for diagnosis of GCA, ultrasound has superior sensitivity but lower specificity. Occasionally, histological evidence of inflammation is restricted to the vasa vasorum, the periadventitial small vessels, or both, which could limit the diagnostic sensitivity of ultrasound for GCA. Moreover, false positive ultrasound results have been described in patients with arteriosclerosis on histology.

Objectives: To compare histologic findings with ultrasound results from patients with suspected GCA included in the TABUL study (a multinational study to assess the relative performance of ultrasound and TAB for diagnosing GCA).

Methods: All patients with newly suspected GCA underwent an ultrasound of both temporal and axillary arteries, followed by a TAB, within 7 days of commencing glucocorticoid therapy. TAB pathological diagnoses were analysed and the different histologic features were compared with the ultrasound results using Chi-square or Fisher exact tests.

Results: Results for TAB and ultrasound were available in 388 patients $(69 \%$ with a final clinician's diagnosis of GCA). An artery was definitely obtained in $363(94 \%)$ TABs; the pathological diagnosis was GCA in $104(29 \%)$ cases, arteriosclerosis in $35(10 \%)$, normal in $203(56 \%)$ and other conditions in $21(6 \%)$ All TABs compatible with GCA also had a final clinician's diagnosis of GCA $(73 \%$ with positive ultrasound). Table 1 shows that ultrasound positivity occurred more frequently in patients where the media was the predominant site of inflammation $(p=0.01)$. The ultrasound result was positive in $9(26 \%)$ cases where TAB was consistent with arteriosclerosis, $8(89 \%)$ of whom had a final clinician's diagnosis of GCA. The ultrasound was positive in $64(32 \%)$ cases where TAB was normal, $52(81 \%)$ of whom had a final clinician's diagnosis of GCA.

\begin{tabular}{|c|c|c|c|}
\hline Histologic features (n patients) & $\begin{array}{l}\text { Ultrasound positive } \\
\qquad(\mathrm{n}=76)\end{array}$ & $\begin{array}{l}\text { Ultrasound negative } \\
\qquad(\mathrm{n}=28)\end{array}$ & $p$ value \\
\hline \multicolumn{4}{|c|}{ Predominant site of inflammatory cellular infiltrate } \\
\hline Predominant intima infiltrate $(n=8)$ & $7(87.5 \%)$ & $1(12.5 \%)$ & 0.679 \\
\hline Predominant IEL infiltrate $(n=13)$ & $10(76.9 \%)$ & $3(23.1 \%)$ & 1.000 \\
\hline Predominant media infiltrate $(n=21)$ & $20(95.2 \%)$ & $1(4.8 \%)$ & 0.010 \\
\hline Predominant adventitia infiltrate $(n=19)$ & $11(57.9 \%)$ & $8(42.1 \%)$ & 0.099 \\
\hline Predominant vasa vasorum infiltrate $(n=4)$ & $2(50 \%)$ & $2(50 \%)$ & 0.293 \\
\hline Predominant transmural infiltrate $(n=39)$ & $26(66.7 \%)$ & $13(33.3 \%)$ & 0.254 \\
\hline \multicolumn{4}{|l|}{ Histologic specific findings } \\
\hline Presence of giant cells $(n=74)$ & $58(78.4 \%)$ & $16(21.6 \%)$ & 0.056 \\
\hline Presence of vessel complete occlusion ( $n=24)$ & $17(70.8 \%)$ & $7(29.2 \%)$ & 0.778 \\
\hline Presence of IEL fragmentation ( $n=86$ ) & $61(70.9 \%)$ & $25(30.1 \%)$ & 0.386 \\
\hline Presence of intimal hyperplasia $(n=91)$ & $65(71.4 \%)$ & $26(28.6 \%)$ & 0.506 \\
\hline
\end{tabular}

Conclusions: Amongst patients with suspected GCA, ultrasound is more likely to be positive when histological inflammation is predominantly present in the intima-media. No significant correlation between histologic findings and negative ultrasound results was found, but the small number of cases with predominant vasa vasorum infiltrates in our cohort limited this analysis. There was only one false positive ultrasound in patients with arteriosclerosis on TAB.

Disclosure of Interest: None declared

DOI: 10.1136/annrheumdis-2017-eular.3544

\section{THU0303 CLINICAL FEATURES AND PROGNOSIS OF ANCA- ASSOCIATED VASCULITIS WITH RENAL INVOLVEMENT AT DIAGNOSIS}

S. Fukui, N. Iwamoto, T. Shimizu, M. Umeda, A. Nishino, T. Koga,

S.-Y. Kawashiri, Y. Hirai, K. Ichinose, M. Tamai, H. Nakamura, T. Origuchi, A. Kawakami. Immunology and Rheumatology, Nagasaki University Graduate School of Biomedical Sciences, Nagasaki, Japan

Background: Kidneys are major organs targeted by antineutrophilic cytoplasmic antibody (ANCA)-associated vasculitis (AAV). Clinical manifestations, laboratory data, and prognosis of AAV with renal involvement at diagnosis are not elucidated. 